\title{
On the effectiveness of care co-ordination services aimed at preventing hospital admissions and emergency attendances
}

\author{
Les Mayhew
}

Received: 20 May 2008 / Accepted: 5 November 2008 / Published online: 16 December 2008

(C) The Author(s) 2008. This article is published with open access at Springerlink.com

\begin{abstract}
Finding alternatives to hospital admissions for older people and helping them to live for as long as possible in their own homes is a key objective of UK health and social policy. However, there is a lack of proof as to whether such alternatives actually work and are costeffective. The research reported in this paper is based on an evaluation of a care co-ordination service with the aim helping people to remain at home and preventing unnecessary hospital admissions and A\&E attendances. An initial evaluation found that the effectiveness of the service was at best marginal. The new method of evaluation described in this paper tracks patient attendance at A\&E departments and hospital stays 12 months before they are accepted into the care co-ordination service and evaluates the resultant savings in health care activity. It finds that the service results in between 14 and 29 saved hospital bed days per client per year and between three and eight A\&E attendances. Whilst the service does not arrest functional decline in individuals, the incidence of falls is significantly reduced, and that the effect on quality of life is neutral to broadly favourable. It finds that mortality levels are higher than in the general population of similar age but this is probably due to selection effects because clients are unhealthier from the outset, and that in the 90+ age group there is no significant difference. Without the benefit of a control group it is not possible to confirm the results with certainty, but corroborating independent evidence is provided that supports the conclusions reached.
\end{abstract}

\section{Mayhew $(\square)$}

Faculty of Actuarial Science and Insurance,

Cass Business School, City University,

London, UK

e-mail: lesmayhew@googlemail.com
Keywords Care co-ordination - Older people . Prevented hospital admissions and A\&E attendance . Functional decline $\cdot$ Quality of life $\cdot$ Evaluation

\section{Introduction}

There is intense interest within the UK health service in finding alternatives to hospital admissions for older people and helping them to live for as long as possible independently in their own homes. Hospital care is not only very expensive, older patients tend to stay longer in hospitals than younger patients, and block beds if there is no suitable place to discharge them to $[9,10]$. The problem is exacerbated when they are frail and there is only minimal support in their home for them to live independently. If it could be shown that being supported at home could prevent hospital admissions and that the support provided was cheaper than admitting people to hospital then it would be worth serious consideration from a public policy as well as provider perspective, especially if quality of life was also improved.

Many admissions to hospital are inappropriate due to a complex interplay between patient characteristics, referral behaviour by medical professionals and other factors [8]. In recognition of policy overlap between limiting hospital based care on the one hand and on the desire of many older people to remain in their own homes on the other, the Department of Health is leading a project called 'Partnerships for Older People Projects' (or POPP), the strategic aim of which is to test and evaluate (through pilots established during 2006-07 and 2007-08) innovative but hugely different approaches that include prevention of admissions to hospital as one of the outcomes. This paper reports on one of the pilots in this programme, based in the 
London Borough of Brent, ${ }^{1}$ for which the author was lead evaluator. Because the pilot is indicating higher savings than is the average among other pilots in the programme ${ }^{2}$ it therefore has wider implications for how prevention programmes may be made to work. Since how to manage the health and other needs of older people is a universal problem in ageing societies, the results reported here are expected to be of general interest, not just in the UK.

The Integrated Care Co-ordination Service (ICCS), formed for the pilot project, has been running since April 2006, although a reduced version, was running for 2 years prior to that. A sustainability plan drawn up after 12 months was pessimistic about future prospects noting that whilst ICCS saved more than it cost the margins were small ${ }^{3}$. The main reason for this was because the evaluation relied on subjective assessments of admission avoidance in the 3-month post-referral period while ICCS was active and not subsequently, and so it failed to take into account the possibility of any savings accruing beyond 3 months that might have altered this conclusion. This paper reports the results of two important changes to the methodology: (a) clients are tracked through the system to ascertain their full admission history before and after intervention, and (b) the follow-up period is extended to 1 year post intervention. It finds that, contrary to initial findings, the impact of ICCS on prevented admissions is much more substantial than previously thought. The key reason, as indicated above, is that the initial evaluation only took into account "savings" whilst the case was active. This paper shows that in fact the full savings become apparent only in the 9 months after ICCS has closed the case (i.e. 1 year), once appropriate support systems had been put in place. If generalised to the whole population this finding would have significant implications for the way in which hospital and community care are funded in the UK.

\section{Concept of prevention}

As health care becomes more expensive, changes in the prioritisation of resources within health and social care for treating and caring for older people have resulted in "a situation where those with low level needs are often left unsupported until they experience a major life crisis" [12]. Initiatives aimed at reducing costs through prevention of hospital admission have tended to take a backseat with the

\footnotetext{
${ }^{1}$ Brent is a suburb of northwest London with a total population of $289 \mathrm{k}$ of whom $30 \mathrm{k}$ are $65+$.

${ }^{2}$ National Evaluation of Partnerships for Older People Projects. Interim Report of Progress Briefing Paper. Cost-Effectiveness - Measuring Effects: Emergency Bed-Day Use, University of Hertfordshire [22], Oct 2007.

${ }^{3}$ Brent Partnerships [4] for Older People Projects-12 months on. May 2007, Internal report.
}

main focus arguably on reducing hospital treatment costs. Good examples are early discharge schemes from hospital such as the provision of intermediate care services [14, 20, 21]. Although there is a history of modelling care delivered in the home (e.g. [2, 11, 15, 16]), research from a preventive perspective is thin on the ground. One arguable consequence is, as Wanless [23] notes, “...progress in reducing delayed transfers from hospital, has not been matched by avoidable [i.e. preventable] admissions..."4.

Examples in the literature show it is possible to reduce hospital admissions, but they are often concerned with patients with specific long term conditions such as congestive heart failure [18]. An alternative but complementary direction of research is based on finding ways to arrest functional decline in older people who have been helped to live at home (e.g. [3, 22]). In general most results show some impact on preventing admissions, but outcomes in terms of improving health, reducing mortality or arresting functional decline are more elusive. A reason for this, as Rubenstein and Stuck [19] note, is that... "not all geriatric programmes are alike. Effective interventions need to have a critical intensity level and be targeted at the appropriate sub-population". Although the literature is agreed that such programmes tend to be inconclusive in these important regards, variants of them are successful in reducing falls or fear of falls, an important cause of attendance in A\&E departments and in emergency admissions [7].

In this paper we are concerned with a specific kind of preventive service that combines in one package different elements of care that are coordinated under a single organizational umbrella. Following a description of what the service is designed to do and how it is delivered, the paper focuses on the methodology and the rationale relating to the achieved reductions in admissions, bed-days used and $A \& E$ attendances and the consequent financial costs and savings. However, it would be insufficient just to deliver savings if the result is a worsening in the quality of life of programme recipients, and so to address this point the paper considers accompanying changes as measured by changes to clients' activities of daily living, the incidence of falls and in well-being.

Key findings are that the service is financially viable and successful in bringing down both admissions and A\&E attendances. It finds that although the 12 month survival rate of clients was $80 \%$ and slightly lower than in the general population, this was most probably due to selection effects (ICCS clients are unhealthier than is the norm). In the $90+$ age range for example it found no significant difference in mortality. Although the service appears to have little effect on arresting functional decline, results show that there is a worthwhile reduction in the incidence

\footnotetext{
${ }^{4}$ Wanless [23]. See summary page xxiv.
} 
of falls following intervention. Meanwhile, a survey of clients showed that quality life remained about the same in $50 \%$ of cases, was improved in $30 \%$ of cases, and became worse in $20 \%$ of cases suggesting the effects of the service in this regard were broadly neutral.

\section{The integrated care co-ordination service}

The Integrated Care Co-ordination Service (ICCS) provides a 'holistic' service to older people over 65 who may be at risk of avoidable hospital admission, premature admission to institutional care, or simply causing concern due to medical, physical, emotional or social issues. It does this by providing assessments and then co-ordinating a range of interventions responding to identified needs, operating across health, social care and other organisational boundaries. These include odd jobs around the home, assistance with moving into more appropriate accommodation, financial advice through the pension and social security system, or referrals to health and social care providers, dentists, opticians, podiatrists, occupational therapists or others in the public, private or voluntary sectors.

It is called a 'preventive service' because the majority of clients are people whose needs have not reached the so-called 'critical and substantial stage' 5 at which point they would qualify for social services but remain at risk of hospital admission. Typically they suffer from one or more long-term conditions that affect their well-being and prevent them from carrying out some of their normal activities of daily living (ADLs). About $70 \%$ of clients accepted into the service are aged $75+$ and $50 \% 85+$, each with typically one or two long term clinical conditions which put them at or just below the social services threshold.

Clients are often people that have had a recent unplanned hospital admissions or A\&E attendance, are experiencing major changes in their lives and have little or no support, or have consistently missed hospital or general practitioner $(\mathrm{GP})^{6}$ appointments. Although health care activity data show an average of one admission and one A\&E attendance per ICCS client in the 9 months prior to referral, there is wide variation around the average with a few admittedly extreme cases for which there were over 20 A\&E attendances and a similar number of admissions. Cases are referred to the service through a range of sources including

\footnotetext{
${ }^{5}$ Local providers of adult social services operate under a framework known as Fair Access to Social Care (FACS), which includes four eligibility bands-critical, substantial, moderate and low.

${ }^{6}$ GPs are family doctors. All residents of the United Kingdom are registered with a GP who provide low level care and act as a gateway to more specialised medical services.
}

families and neighbours, although in about $50 \%$ of cases the main referrer is the client's own GP.

Care co-ordinators visit clients in their homes and make an assessment before commissioning a range of services from partnering agencies. These include free or low cost statutory services that might have been provided anyway but not necessarily on the same timely basis, and voluntary and other services $^{7}$. The co-ordinators then follow up the clients for a period of about 3 months and then close the case once the appropriate services are in place or the case is closed for other reasons (e.g. death or transferral to nursing or residential care). In this regard, the following two brief cases studies are informative and illustrate the divergence in circumstances and courses of action available to the co-ordinators.

The first is $\mathrm{Mr} \mathrm{A}$, who was an 82 year old diabetic man with poor mobility, loss of balance and confusion. He had missed a number of hospital appointments and there were no working lights in his kitchen putting him at significant risk of an accident. ICCS referred $\mathrm{Mr} \mathrm{A}$ to a handyman who fixed various things around the house to make it safer and more comfortable. Transport was arranged for him to attend hospital appointments at a local memory clinic. Discussion with his GP and pharmacist resulted in his prescriptions being supplied and delivered to his home. Meals on wheels and dietary advice were supplied by local social services and equipment to support other activities of daily living.

The second case study is Mrs B a 73 year old woman with a history of memory loss and confusion. She lived with her daughter and granddaughter but no longer recognised them. She suffered with anaemia but no longer had B12 injections because of the difficulty of arranging them. She was also aggressive to her main carer which was her daughter. ICCS referred Mrs B to the local community mental health team, introduced a nurse to support her daughter and referred her to a GP and psychologist. As the family lived in an over-crowded two bedroom apartment she was also referred to a housing worker to consider the possibility of re-housing. The resumption of B12 injections, new medication and support considerably improved her behaviour, and respite care which was also initially recommended became unnecessary such was the improvement in her condition.

\section{Methodology}

\section{(a) Research issues arising}

The evaluation methodology adopted has much in common with other studies that aim to measure reductions in hospital

\footnotetext{
${ }^{7}$ Examples include befriending services, a toe-nail clipping service, and decorating and odd job service, dental and optician check ups.
} 
admissions, although details may vary in terms of the nature of the intervention. For example Myers et al [17] found that re-hospitalisation rates and use of A\&E, and nurse visits were reduced through the use of tele-monitoring services for patients with congestive heart failure. Henderson and Scott [13] found that the cost of treating stroke patients in a GP-led hospital instead of in an acute hospital was less than previously but that related health outcomes were unchanged. Rich et al [18] concluded that a nurse-directed, multidisciplinary intervention can improve quality of life and reduce hospital use and medical costs for elderly patients also with congestive heart failure. An important difference here is that ICCS is not simply about health care and may involve multiple interventions, but in other respects the methodological challenges are similar.

Approaches to similar evaluation problems in the literature are, for the most part, based on 'pre-re-test post test control group' experimental designs [5]. In the absence of a control group, these authors observe that such study designs are problematic because they are open to the criticism that changes in observed outcomes could have occurred anyway due to other reasons. Whilst the possibility of using a control group was initially considered here, we were forced to reject it on both ethical and practical grounds. Since selection into ICCS is based on criticality of need it would have been extremely difficult to deny services to one old person living alone and in frail health and not to another in a similar situation. The alternative of separating the pilot into areas or GP practices was also rejected on practical grounds because of the difficulty of matching patients on morbidity, functionality and socio-economic criteria without encountering the same ethical objections as before [1].

\section{(b) Data considerations}

The chosen method of evaluation used is a classic 'before and after approach' in which the hospitalisation, bed-day usage and A\&E attendance history of all clients were monitored on a monthly basis pre- and post- ICCS intervention. The resulting time series were then modelled to determine not only actual consumption of these services, but what consumption would have been if pre-referral trends had continued. Public health death registration data was used to track clients that died and information on the condition of clients was collected monthly by care coordinators (e.g. on ADLs, and incidence of falls). Information on referrals made to other services and the services actually rendered were also collated and reported on a monthly basis. Full details of these are provided in a separate report ${ }^{8}$.

\footnotetext{
${ }^{8}$ The Economic, Health and Social Benefits of Care Co-Ordination for Older People: The Integrated Care Co-ordination Service (ICCS). Cass Business School, 2008 [6].
}

Even with such an approach, the potential problem remains of falsely assigning cause and effect. For example, was the fall off in hospital activity due to ICCS or could it have been caused by the withdrawal of hospital based services? This phenomenon, known also as 'regression to the mean', occurs because people are invited to join a programme based on a set of circumstances that might revert back to their normal state even without the intervention for unconnected reasons $[5]^{9}$. To address this problem, a strategy was adopted of using corroborating evidence where possible so that findings could to some extent be independently verified. One example of this involved splitting the data into cohorts with different start and end dates, noting that if such an effect as the withdrawal of hospital services had been evident it would have been easily observable. The fact that the same response was obtained in each case, regardless of start and end date, gave credence to the notion that the programme had an impact.

Another example was information provided by care co-ordinators who reported each month whether their actions avoided an admission or an A\&E attendance. As discussed later, their independent findings indicated that savings fell in the middle of the upper range predicted by the model. We also monitored inpatient services, both admissions and bed-day utilisation, so that we could ascertain if there was an 'ICCS effect' on the wider health economy. In this case, we found that the overall amount of inpatient activity among the $65+$ population held up over the whole period of the pilot. This meant that ICCS clients whose hospital attendance had reduced were effectively being substituted by other patients but that there was no alteration in overall patient throughput that might have caused this effect. This finding had deeper significance because it indicated that whilst ICCS reduces admissions and bed-days it does not necessarily cause total hospital activity to reduce, and that if there is an effect it would be on reduced waiting times e.g. for elective admissions ${ }^{10}$.

\section{Results}

The following sections describe in more detail the analysis and results based on three measures used to measure the

\footnotetext{
${ }^{9}$ Campbell and Stanley note that 'regression toward the mean' is an ubiquitous phenomenon, not confined to pre-and post testing.

${ }^{10}$ In a health care system like the UK's that is free at the point of use it is not unusual for demand to rise to the level of capacity in this case of a hospital.
} 
Fig. 1 Average admissions to hospital per client per month before and after ICCS intervention showing standard error bars

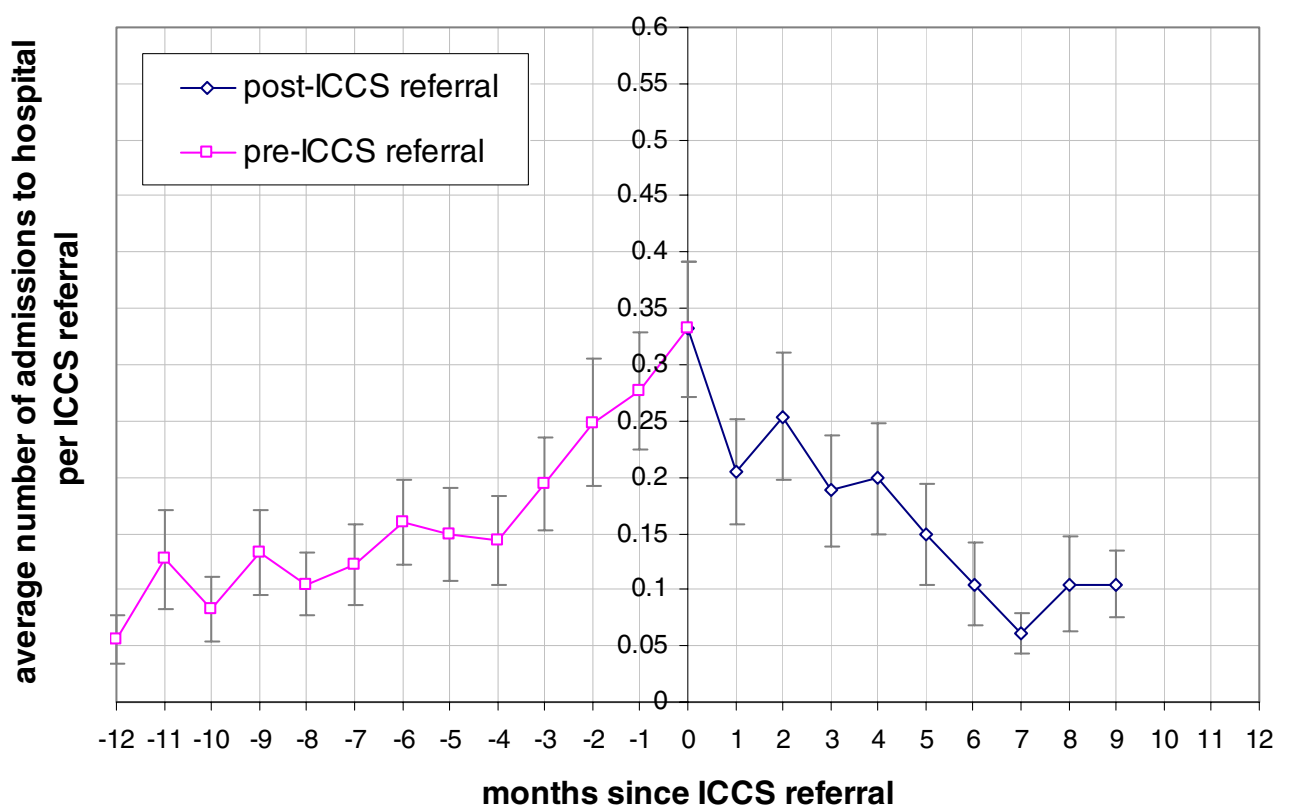

impact on hospital based care: admissions, bed-day utilisation and A\&E attendance. We proceeded as follows:

1. The NHS numbers of ICCS clients referred after April 2006 were obtained from the register of patients of practising GPs anywhere within and outside Brent ${ }^{11}$.

2. Each number was then tracked to ascertain from April 2004 onwards the number of hospital admissions, beddays consumed and number of A\&E attendances at any hospital.

3. The case histories of each client were then compared in the periods before and after ICCS referral from three perspectives: hospital; admissions, bed-day usage and A\&E attendance.

The sample consisted of 340 cases that had been referred to ICCS between the 4th April 2006 and the 30th of April 2007 and who were still alive at 31 st October 2007. To confirm that the results observed were not an accident of management, of timing or of either random or systemic effects we split cases into four groups: those for which we had data for at least 4 months post-referral, and then 6,9 and 12 months respectively (340,249, 181 and 93 cases altogether).

(a) Analysis of avoided admissions

Figure 1 shows the pattern of average hospital admissions per month per client 12 months prior to referral and 12 months after referral for each of the series for clients with at least 9 months post-referral history. Error bars

\footnotetext{
${ }^{11}$ All residents of the United Kingdom are given a unique National Health Service (NHS) number at birth or on first registration with a GP.
}

equating to one standard error around the average at each data point are also included, from which it can be visually confirmed that there is an underlying pattern to the data and that average admission rates are significantly different from zero. Monthly averages range from around 0.05 admissions per month per client in the 12 months prior to intervention, to 0.34 per month per client at the point of intervention, falling again post-intervention approximately back to the same point 21 months earlier.

In Fig. 2 all four hospital admissions' series are plotted in one graph in order to check for possible timing differences and external influences. We have retained the error bars for the 9-month follow up sample in order to show that different cuts of the data do not materially differ from each other using one standard error as a basis for comparison. Note that the 12- month follow up series is more erratic than the other three samples due to a much smaller sample size of only 93 cases. These graphs are based solely on admissions although similar test results, reported later, are provided for bed-day utilisation and A\&E attendance.

The argument of a rising trend in projected admission would not be sustainable if the peak and then decline in admissions at the point of referral was simply a random blip over a longer period. Figure 3 analyses admission history in the period 24 months before ICCS intervention and in the 9 month period post-intervention. It shows that, whilst admissions fluctuate from month to month, the steep climb in admission rate prior to the point of referral is not present at any point in the previous 24 months so that we can be more confident that the change that occurs after intervention is a true consequence of ICCS activity, and not of miscellaneous random effects. 
Fig. 2 Average admissions to hospital per client per month before and after ICCS intervention after splitting the data into four series

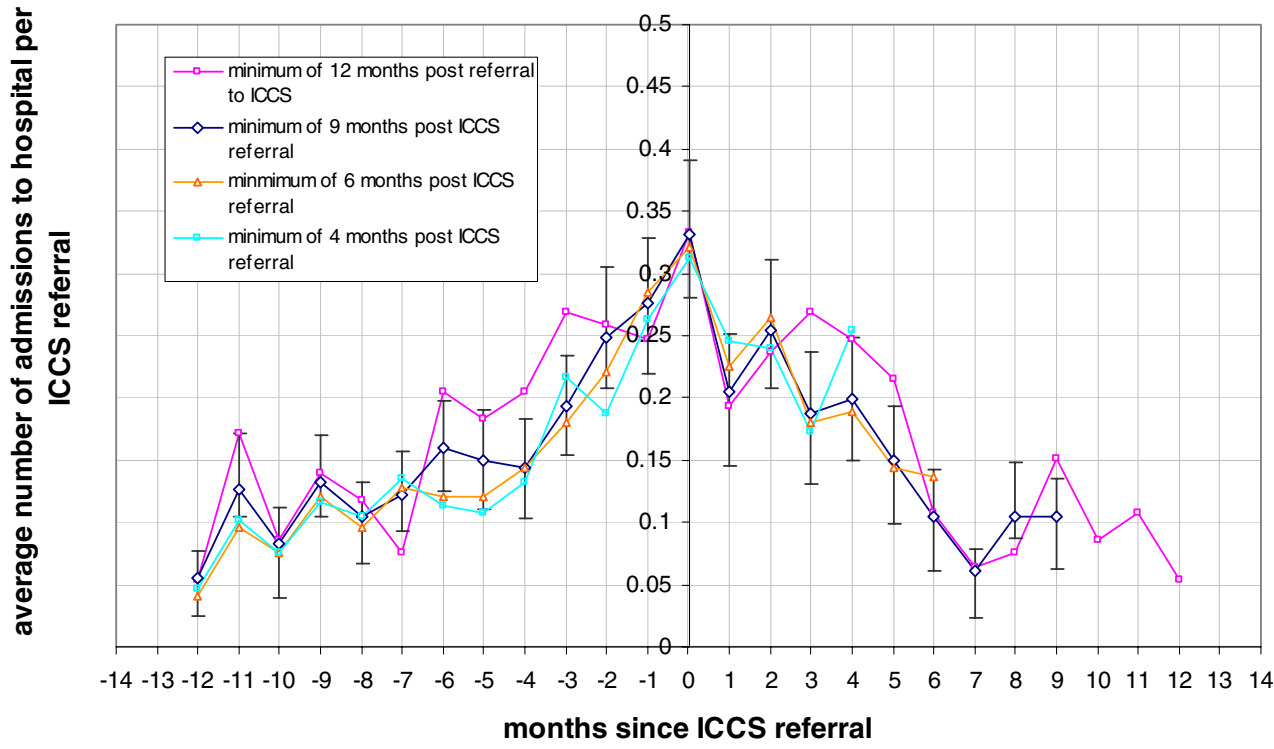

\subsection{Trend analysis}

We now turn to the issue of fitting trend lines to the data before and after referral, the basis for which will inform the calculation of any savings from ICCS intervention. The approach used and the assumptions made are similar whether we measure admissions, bed-days or A\&E attendance and so will not be repeated for each case. The sample of data points used comprised 181 cases referred between 4th of April 2006 and 1st of December 2006, all of which have a minimum of 9 month post-referral history. Note that if we had sought only cases with a minimum of 12 months history the sample would have been smaller but the time frame longer, and if we had sampled cases with less than 9 months history the sample would have been larger but the time frame shorter. Using a 9-month follow up is therefore a compromise between time frame and sample size.

The key issue is how admissions would have continued if ICCS had not intervened at the point when it did is a critical aspect of the methodology and so was necessarily subjected to considerable amount of analysis. Although previous figures show that the admission pattern accelerates prior to referral and then decelerates after, there is little theory available to indicate the functional form the trend line should take other than it should probably be monotonic. Choosing between different functional forms of regression line on purely statistical grounds would not necessarily prove productive, especially where there was close similarity in goodness of fit (e.g. a 2 nd degree polynomial, versus an exponential trend line versus a linear trend).

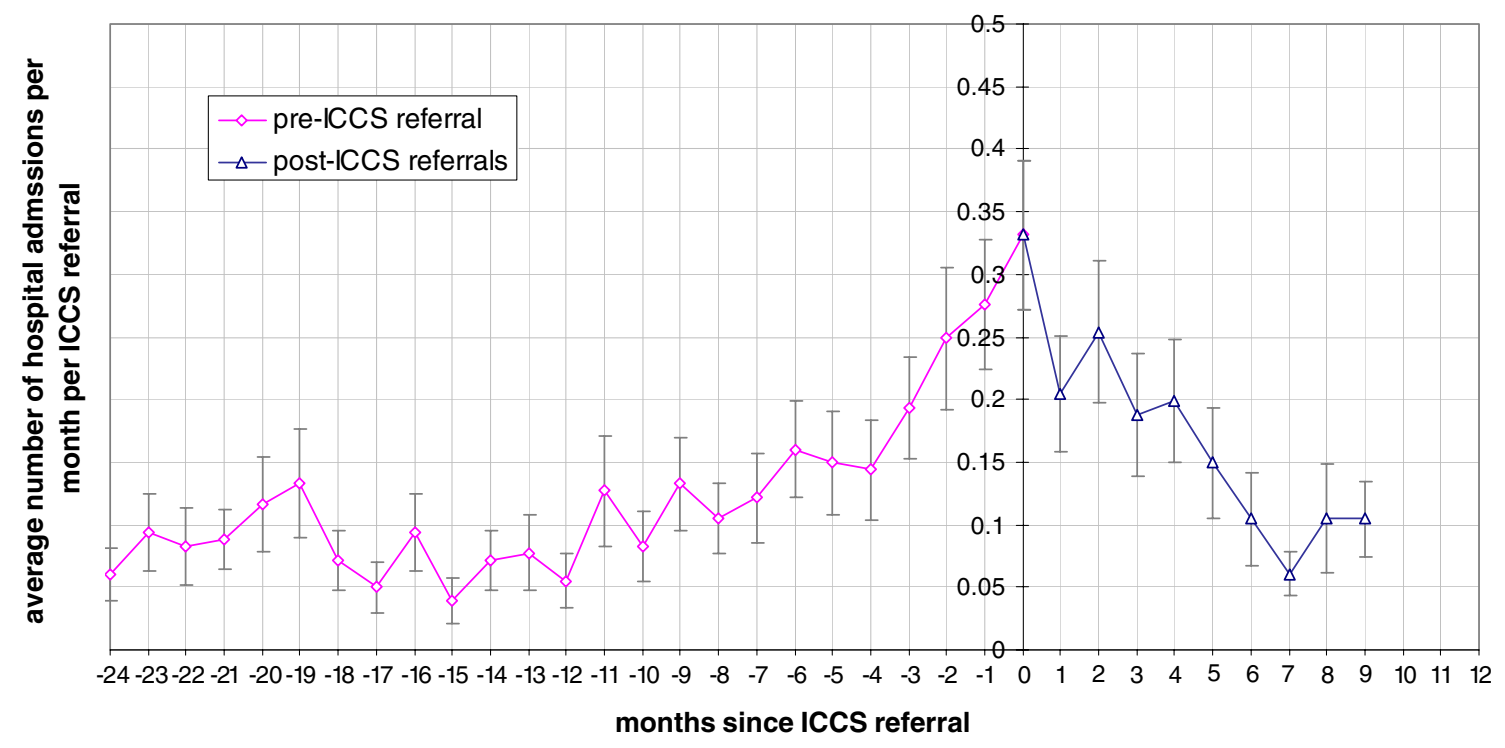

Fig. 3 Monthly average admission activity per ICCS client in the 24 month pre-referral period and the 9 month post-referral period 
Recognising that there was bound to be uncertainty in using 13 data points to project forward a trend for a similar period of time, we considered it more plausible to present a range of outcomes based on more than one fitted trend line. After experimentation with different cuts of the data and functional forms, this led to the decision to define two types of trend line, one an exponential (accelerating) trend and the other linear, based on a constant growth rate. Our logic was that as long as this range contained an envelope of probable outcomes that would still deliver net savings, we would be on safer ground in terms of recommending a continuation of the service to health care managers if the analysis suggested this was the case.

In practical terms an exponential trend line has several useful properties including the fact that it is monotonic. Likewise a linear trend also has simple properties and is well understood by health care managers. The results show that an exponential trend line is a slightly more accurate indicator of the underlying statistical trend in the case of pre-referral admissions, but gives higher projected number of prevented admissions. A linearly increasing trend line on the other hand fits the data almost as well but gives a more conservative projected number of prevented admissions. Regression results are shown in Table 1 and shows the values of the slope parameters $b$ and constant $A$ or $\log A$, including standard errors of both, t-ratios and values for $\mathrm{R}$-squared ${ }^{12}$. Pre- and post-referral regressions are based on 13 and ten data points respectively. The pre-referral value of R-squared is 0.84 in the exponential case and 0.82 in the linear case. With fewer post-referral data points on which to base admissions, R-squared is less at 0.76. All regression parameters are statistically significantly different from zero at the 0.01 level.

The concept of avoided admissions is shown in Fig. 4 and is now explained in further detail. On the vertical axis is the average number of admissions per client pre- and post-referral (as previously) but now the trend lines have been added for clarity. The areas to the right of the origin represent actual and prevented admissions and may be found by mathematical integration under the curves. The area under the curve to the left of the origin represents actual admissions and may be similarly found using integration. The necessary analysis to derive this area and then to convert it into financial savings is shown in a separate section which brings the main elements of the

\footnotetext{
${ }^{12}$ In the exponential case the estimating equation is $\log y_{t}=$ $\log A+b t$, where $\mathrm{y}_{t}$ is the number admissions in time period $\mathrm{t}$ and $\log A$ and $b$ are regression constants. R-squared values are typically higher in the pre-referral phase because there are more data points. This applies whether admissions, bed-days or A\&E attendance are used.
}

Table 1 Results from fitting an exponential and linear trend curves to admissions date pre- and post-referral to ICCS

\begin{tabular}{lccc}
\hline Statistical model & \multicolumn{2}{l}{ Admissions } & \\
\cline { 2 - 4 } & \multicolumn{4}{l}{ Constant $\log A, A$} & Slope $b$ & $R^{2}$ \\
\hline \multicolumn{2}{c}{ Trend line based on actual pre-ICCS admissions } \\
-exponential & -1.2258 & 0.1153 & 0.84 \\
S.E & 0.1078 & 0.0152 & \\
(t) & $(11.4)$ & $(7.6)$ & \\
-linear & 0.2742 & 0.0184 & 0.82 \\
S.E & 0.0184 & 0.0026 & \\
(t) & $(14.9)$ & $(7.1)$ & \\
Trend in actual admissions 9 month post-ICCS referral & \\
-exponential & -1.2214 & -0.1467 & 0.76 \\
S.E & 0.1547 & 0.029 & \\
(t) & $(7.9)$ & $(5.1)$ & \\
\hline
\end{tabular}

evaluation together. For the moment we continue with a description of the concepts and key results.

In more detail the defintions of each area under the curves are as follows:

- (A) Actual admissions in the period up to referral. The total number of admissions is given by the area under the curve. This segment shows an accelerating trend prior to referral.

- (B) Actual admissions post-referral. This segment shows a decelerating trend in admissions post-referral but admissions never decline to zero.

- (C) Projected number of admissions post-referral (lower bound). Extra admissions that would have occurred, assuming that the 12 month trend in the average monthly admissions prior to referral had continued at a constant rate in the following 12 months (i.e. a linear trend).

- (D) Projected number of admissions post-referral (upper bound). Extra admissions that would have occurred over and above $\mathrm{C}$ based on an accelerating rate of admission prevention (i.e. an exponential trend).

We define $\mathrm{B}+\mathrm{C}+\mathrm{D}$ as the upper bound admissions that would have occurred in the absence of ICCS, B+C as the lower bound admissions, $\mathrm{C}+\mathrm{D}$ as the upper bound net avoided admissions and $\mathrm{C}$ as the lower bound net avoided admissions. From inspection of Fig. 4 it can be seen that A and $\mathrm{B}$ are more or less equal i.e. the number of admissions 12 months prior to ICCS equals the number of admissions in the 12 months post-ICCS (in fact 1.9 admissions prior to referral and 1.7 admissions post-referral). At the point of referral (zero on the horizontal axis), the predicted admission rate was 0.3 admissions per month per ICCS client. After 12 months this would have fallen to 0.05 per month, over a quarter of the rate at referral. Thus by only looking at actual 
Fig. 4 The pattern of admissions pre- and post-ICCS intervention with fitted trend curves applied (key: $\mathrm{A}=$ actual admissions in previous 12 months; $\mathrm{B}=$ actual admissions 12 months post-ICCS intervention; $\mathrm{C}=$ prevented admissions based on constant growth assumptions resulting from ICCS intervention; $\mathrm{C}+\mathrm{D}=$ prevented admissions based on accelerated trend resulting from ICCS intervention)

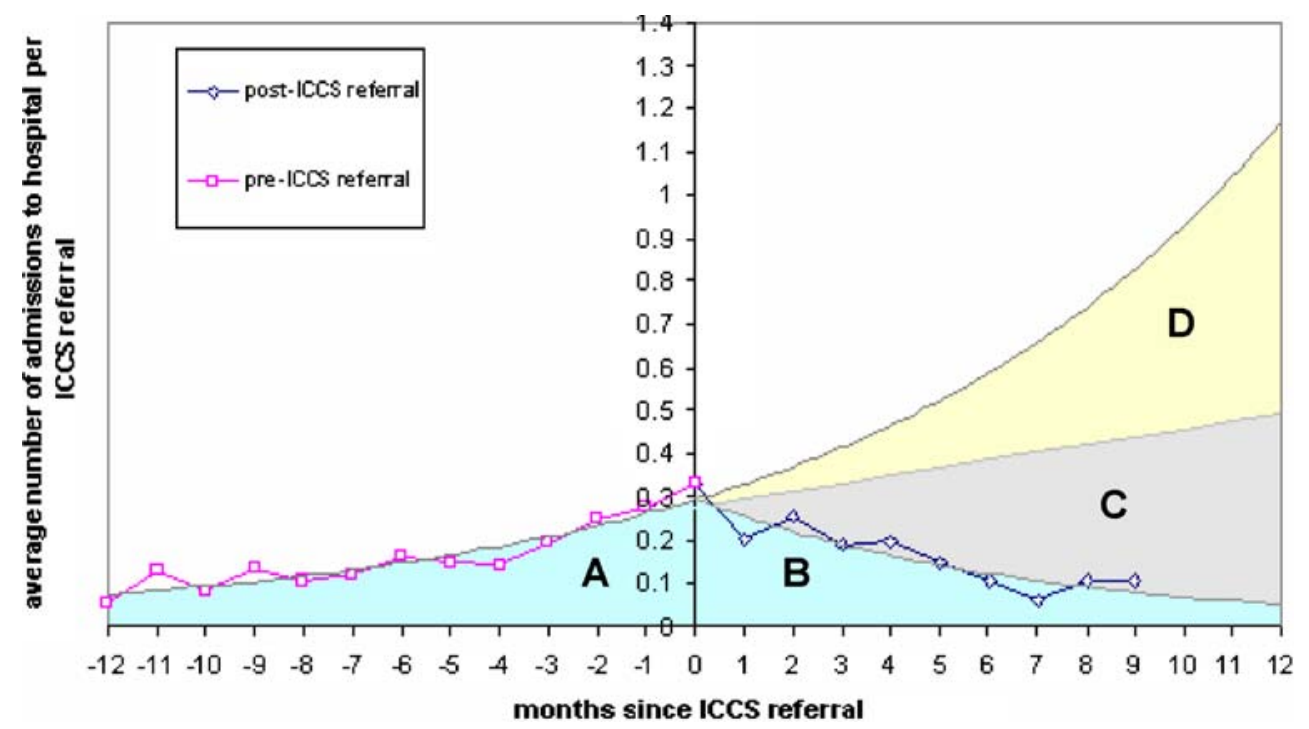

admissions before and after referral one would be likely to draw the conclusion that ICCS was ineffective (i.e. admissions were unchanged). Although we find that admissions are similar before and after referral, the crucial difference is that $\mathrm{A}$ is an increasing trend and $\mathrm{B}$ is a decreasing trend.

Based on a constant growth rate (i.e. lower bound assumption), analysis shows that, in the absence of ICCS, a typical client would have been admitted 4.6 times in the 12 month post-referral period. In fact, as the analysis of area B shows, a typical individual was actually admitted 1.7 times, so representing a saving of 2.9 admissions per client. Based on an accelerated growth rate an individual would have been admitted 7.6 times and so the net saving in admissions becomes 5.9 per client (1.7-7.6). These findings are summarised in Table 2 and imply that in a typical annual caseload of 500 referrals the net total reduction in admissions would lie between $1.2 \mathrm{k}$ and $3.0 \mathrm{k}$ per year.

How can we be sure these results fall within a plausible range? In the monthly information system care co-ordinators were asked to judge whether their actions helped to prevent an admission. Based on their information, ICCS avoided 5.3 admissions per year per client, a figure which falls between the upper and lower bound results in Table 2 but errs towards the upper bound. Further confirmation that admission frequencies can rise to high levels is given by independent data on 3,000 cases in the 12-month period before death, which indicated 3.5 admissions on average.
Are there savings beyond 12 months? For practical reasons determined by the length of the project the time horizon used was arbitrarily defined as 12 months postreferral for clients that survived. Longer term avoided admissions are conditional on the client remaining alive beyond the 12 month period and being able to live reasonably independently. When a patient dies all health care ceases and projected savings shown in the charts stop at that point. This has potential implications for hospital admission rates bed day utilisation and A\&E attendance and therefore affect savings calculations. The impact of mortality within 12 months of referral and how its effects were taken into account requires separate consideration and is discussed later.

\section{(b) Avoided bed-days}

In this section we repeat the previous analysis but using bed-day utilisation as opposed to admission frequency. Since length of stay can vary, bed-days consumed are potentially a more accurate measure of savings than admissions and so tend to be proportional to the true underlying costs to the health economy. Figure 5 shows the results obtained after splitting the data into four series which, as is seen, are very similar to the chart for admissions but with some subtle and important differences. For example, it is noteworthy that the series are a little more erratic than was the case for admissions, which in practical

Table 2 Changes in admissions following ICCS intervention-upper and lower bounds

\begin{tabular}{lccc}
\hline Category of admission with ICCS service & Admissions per ICCS client & Total admissions based on ICCS caseload of 500 p. annum \\
\hline A & admissions in previous 12 months & 1.91 & 954 \\
B & 12 month post-referral admissions & 1.66 & 832 \\
C & prevented admissions (lower bound) & -2.95 & $-1,476$ \\
C+D & prevented admissions (upper bound) & -5.95 & $-2,973$ \\
\hline
\end{tabular}


Fig. 5 Bed-day utilisation in the 12 months pre- and post-referral to ICCS after splitting the data into four series

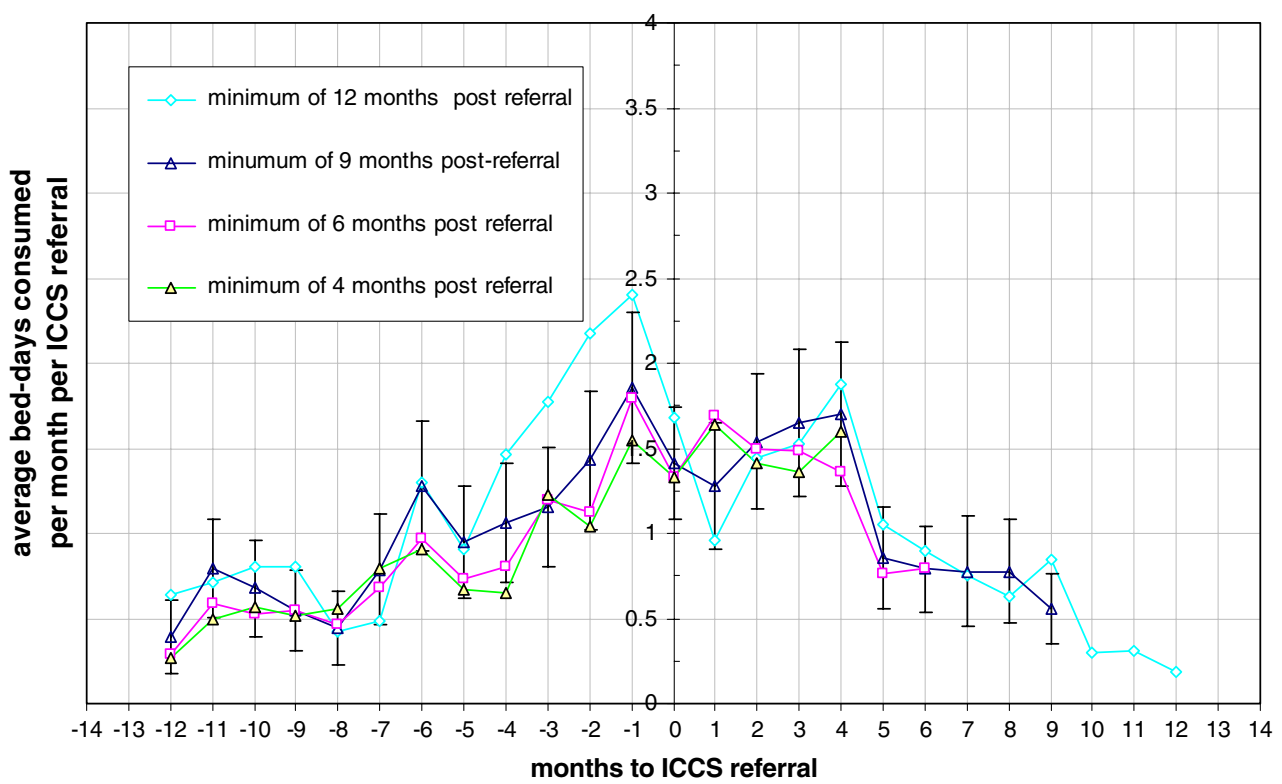

terms means that the quality of fit of the regression equations is inferior as compared with admissions. This finding tends to lend further support to the strategy of including an upper and lower bound in order to err on the cautious side.

The corresponding regression results are shown in Table 3 and show that R-squared values are reduced, reflecting the slightly more erratic nature of the data but that the regression constants and slope coefficients remain statistically significantly different from zero at the 0.01 level of probability. In this case however the linear trend line gives a slightly better fit than the exponential trend based on Rsquared values and standard errors of the regression parameters. Figure 6 shows the same trend pattern as before with the accompanying analysis set out in Table 4. It indicates that in the pre-referral phase a typical ICCS client would have spent 11.4 days in hospital and post-referral 11.6 days. The 12-month value of the bed-days per client saved as result of the intervention however is 14.2 days based on the lower bound estimate and 28.7 days based on the upper bound estimate. On the basis of 500 cases per year and an average cost of $£ 300$ per bed-day ${ }^{13}$ this would imply a post-referral cost of $£ 1.74 \mathrm{~m}$ for those cases hospitalised, and a saving of $£ 2.13 \mathrm{~m}$ based on avoided bed-days (lower bound) and $£ 4.31 \mathrm{~m}$ (upper bound).

We cannot know the number of days that clients would have spent in hospital in the event that an admission had not been deferred or delayed and from visual inspection of

\footnotetext{
$\overline{13}$ At the time of the evaluation $£ 300$ per bed-day was the rounded average value of a bed-day in an acute hospital based on services commissioned by Brent Primary Care Trust
}

bed-day utilisation in the post-referral phase there is greater fluctuation than was the case under admissions data. However, some indication of the reasons for this is given by the trend in average length of stay for those that had been admitted during the period of pre- referral and postreferral. This effect is shown in Fig. 7, which indicates a rising trend in length of stay over the period. One possible explanation for this increase is that the clinical condition and frailty of clients tends to worsen so that if they are admitted they stay for longer. For example, we found that in the 12 months prior to referral average lengths of stay were 6.1 days rising to 8.4 days 12 months post-referral.

\section{(c) Avoided A\&E attendances}

A similar analysis was undertaken for A\&E attendances, with entirely consistent results to the two previous cases. However, because it is a different domain of health care activity, the results arguably lend further weight of evidence that there is an 'ICCS effect'. Figure 8 shows the attendance histories of clients split as previously into four series comprising clients that had completed a minimum of 3 months, 6 months, 9 months and 12 months post-ICCS referral history. Units on the vertical axis are the average number of attendances per month per ICCS client, and range from under 0.1 visits per month 12 months prior to intervention to almost 0.3 attendances per month at the point of referral. Again the results show that, regardless of start and end date, the patterns are remarkably similar suggesting that when the intervention occurred is independent of the impact that it has made. This means it is reasonable to conclude that this is not a caseload or case type effect over time, but more likely to be a function of the intervention itself. The corresponding regression results are 
Table 3 Regression results from fitting exponential and linear trend curves to bed-day utilisation data pre- and post-referral to ICCS

\begin{tabular}{|c|c|c|c|}
\hline \multirow[b]{2}{*}{ Period and statistical model } & \multicolumn{3}{|l|}{ Bed-days } \\
\hline & Constant $\log A, A$ & Slope $b$ & R-squared \\
\hline \multicolumn{4}{|c|}{ Trend line based on actual pre-ICCS bed-day utilisation } \\
\hline -exponential & 0.5149 & 0.1050 & 0.74 \\
\hline S.E & 0.1323 & 0.0187 & \\
\hline$(\mathrm{t})$ & $(3.9)$ & $(5.6)$ & \\
\hline -linear & 1.5654 & 0.0971 & 0.76 \\
\hline S.E & 0.1175 & 0.0166 & \\
\hline$(\mathrm{t})$ & $(13.3)$ & $(5.8)$ & \\
\hline \multicolumn{4}{|c|}{ Trend in actual bed-day utilisation 9 months post-ICCS } \\
\hline -exponential & 0.5541 & -0.1105 & 0.71 \\
\hline S.E & 0.1337 & 0.025 & \\
\hline$(\mathrm{t})$ & $(4.1)$ & $(4.4)$ & \\
\hline
\end{tabular}

shown in Table 5 and show that the quality of fit is, if anything, an improvement on the regression results for admissions and bed-day utilisation. R-squared values range from 0.77 to 0.86 which are higher than in either of the previous cases. Again regression parameters are statistically significantly different from zero at the 0.01 level of probability.

Figure 9 shows the same format as for previous charts with areas of prevented attendances indicated. Without ICCS intervention the number of visits to A\&E per month would have increased from less than 0.1 visits per client per month to 1.7 visits per month at the end of the period (upper bound). Over the whole 12 month post-ICCS referral the results show that total visits would have occurred on 4.09 (lower bound) and 9.07 (upper bound) occasions. However, the actual number of attendances per client with ICCS engagement is around 1.25, giving a net saving of 2.84 and 7.81 attendances per client as shown in Table 6. Based on a cost of $£ 200$ per attendance ${ }^{14}$, including allowance for an ambulance transport to hospital this would result in gross annual savings of between $£ 282 \mathrm{k}$ and $£ 781 \mathrm{k}$ on A\&E attendance figures assuming 500 referrals per year. Again this may be contrasted with the judgement of the ICCS care co-ordinators whose actions they estimated to have saved six A\&E attendances per client per year, a figure which falls between the upper and lower bound. Finally it is noteworthy that the number of attendances predicted by the model is higher than the number of admissions reported above, a finding that is consistent with observation that not all A\&E attendances would necessarily lead to an emergency admission.

\footnotetext{
${ }^{14}$ Rounded average costs based on Brent figures at time of evaluation including cost of ambulance journey.
}

\section{Method of conversion into financial cost/savings}

Thus far we have merely stated the results of the analysis in terms of saved admissions, bed-days or avoided A\&E attendances and not how the calculations of financial estimates were made. We now bring together the elements of this analysis on which the evaluation depends. We are interested in obtaining the financial values for the number of avoided bed-days and A\&E attendances as our measures of health care consumption. Since we have no reliable information on the patterns of activity after 12 months we arbitrarily cut off the analysis at this point for evaluation purposes i.e. $\mathrm{t} \leq 12$.

Turning to the upper bound estimate, let the exponential rate of growth of bed-days per client per month or number of A\&E attendances after the point of referral without ICCS intervention be:

$y_{1}=\phi_{1} \exp \left(\phi_{2} t\right) \quad t \leq 12$

Similarly, let the linear extension after the point of referral without ICCS intervention be:

$y_{2}=\beta_{1}+\beta_{2} t \quad t \leq 12$

Let the actual number of admissions or A\&E attendances post-referral following ICCS intervention be:

$y_{3}=\gamma_{1} \exp \left(-\gamma_{2} t\right) \quad t \leq 12$

Where

$t$ time elapsed since referral to ICCS

Here $\phi_{i}, \beta_{i}, \gamma_{i}$ are parameters previously estimated in Tables 1, 3 and 5, where. $i=1$ is regression constant, $A$, and $i=2$ is slope parameter, $b$. Note that in the exponential trend cases $\phi_{1}, \gamma_{1}=\exp (A)$. 
Fig. 6 Average bed-days consumed per client per month preand post-ICCS referral including prevention effects

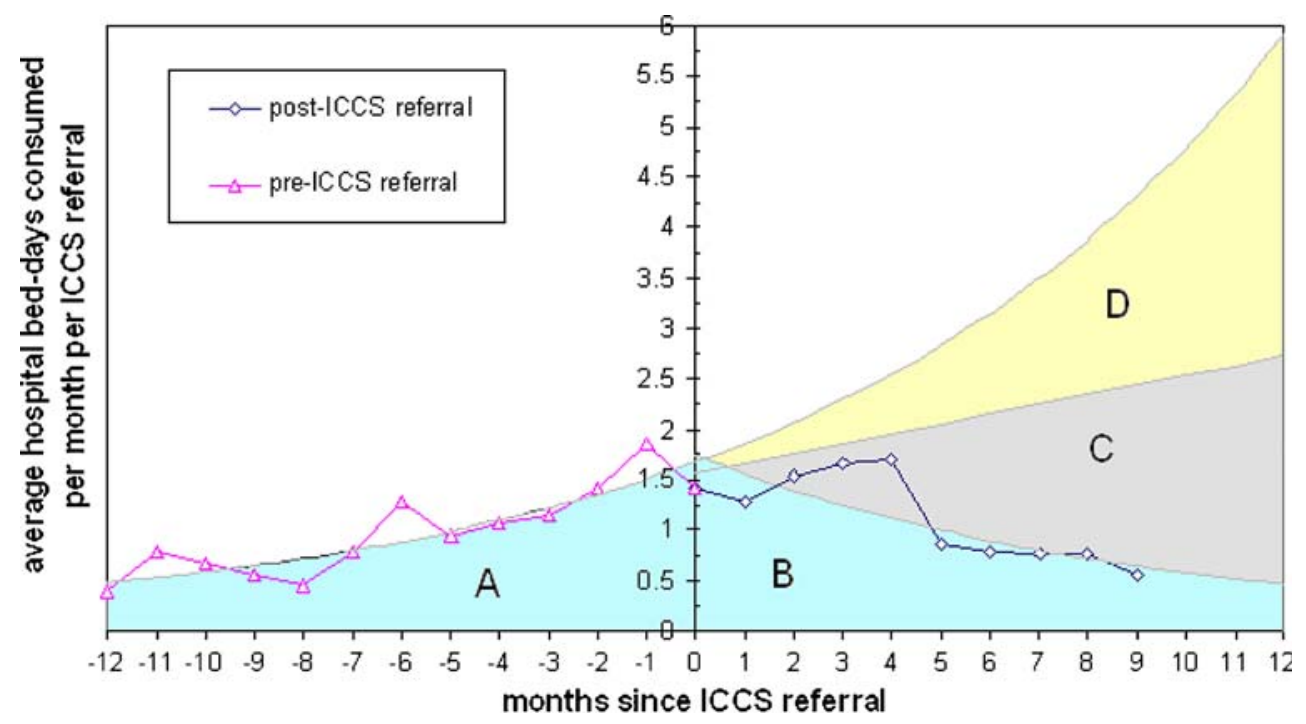

If $t>12$ months we simply assume

$y_{1}=y_{2}=y_{3}=0$

Integrating between $t=0$ and $t=\mathrm{T}$ (i.e. 12 months postreferral) the number of avoided bed-days per client or $\mathrm{A} \& \mathrm{E}$ attendances (upper bound) is given by the area $\mathrm{C}+\mathrm{D}$ :

$C+D=\frac{\phi_{1}}{\phi_{2}}\left[\exp \left(\phi_{2} T\right)-1\right]-\frac{\gamma_{1}}{\gamma_{2}}\left[\exp \left(-\gamma_{2} T\right)-1\right]$

Integrating between $t=0$ and $t=\mathrm{T}$ the number of avoided bed-days (lower bound) is given by areas $\mathrm{C}$ :

$C=\frac{T}{2}\left[2 \beta_{1}+\beta_{2} T\right]-\frac{\gamma_{1}}{\gamma_{2}}\left[\exp \left(-\gamma_{2} T\right)-1\right]$

In order to determine financial savings we need to scale the results by the cost per bed-day or A\&E attendance. There are no assumed economies of scale at current operating levels and so we assume simple average costs per bed-day or attendance. The upper and lower bound savings in any month $n$ consist of the cumulated savings of referrals in previous months $(i=0$ to $i=n$ ) from the commencement of the service plus savings from the current month. The gross savings in month $n$ is hence given by:

Upper bound

$S_{n}=c \sum_{i=1}^{i=n} r_{i} \sum_{t=n}^{t=n-i+1}\left(y_{1}(t)-y_{3}(t)\right)$

Lower bound

$S_{n}=c \sum_{i=1}^{i=n} r_{i} \sum_{t=n}^{t=n-i+1}\left(y_{2}(t)-y_{3}(t)\right)$

Where

$c=$ cost per bed day or A\&E attendance

$r_{i}=$ number of accepted referrals in month $i$

The net savings (gross savings minus administration costs, $a$ ) are then given by:

$S=\sum_{n=1}^{n=N}\left(S_{n}-a_{n}\right)$

The combined net savings is given by the sum of both bed-days and A\&E attendance expressed in the above which can then be converted to a net present value as

Table 4 Changes in bed-days following ICCS intervention - upper and lower bounds (one bed-day $=£ 300$ )

\begin{tabular}{llcrr}
\hline & Bed-day category of admission & $\begin{array}{l}\text { Post-referral average change } \\
\text { in bed-days per client }\end{array}$ & $\begin{array}{l}\text { Total bed-days based } \\
\text { on ICCS caseload }\end{array}$ & Cost/saving (£ms) \\
\hline A & bed-days in previous 12 months & 11.42 & 5,708 & 1.71 \\
B & 12 month post-referral bed-days & 11.57 & 5,784 & 1.74 \\
C & prevented bed-days (lower bound) & -14.21 & $-7,104$ & -2.13 \\
C+D & prevented bed-days (upper bound) & -28.71 & $-14,355$ & -4.31 \\
\hline
\end{tabular}


Fig. 7 Trend in average length of stay pf clients admitted to hospital pre- referral and post-referral

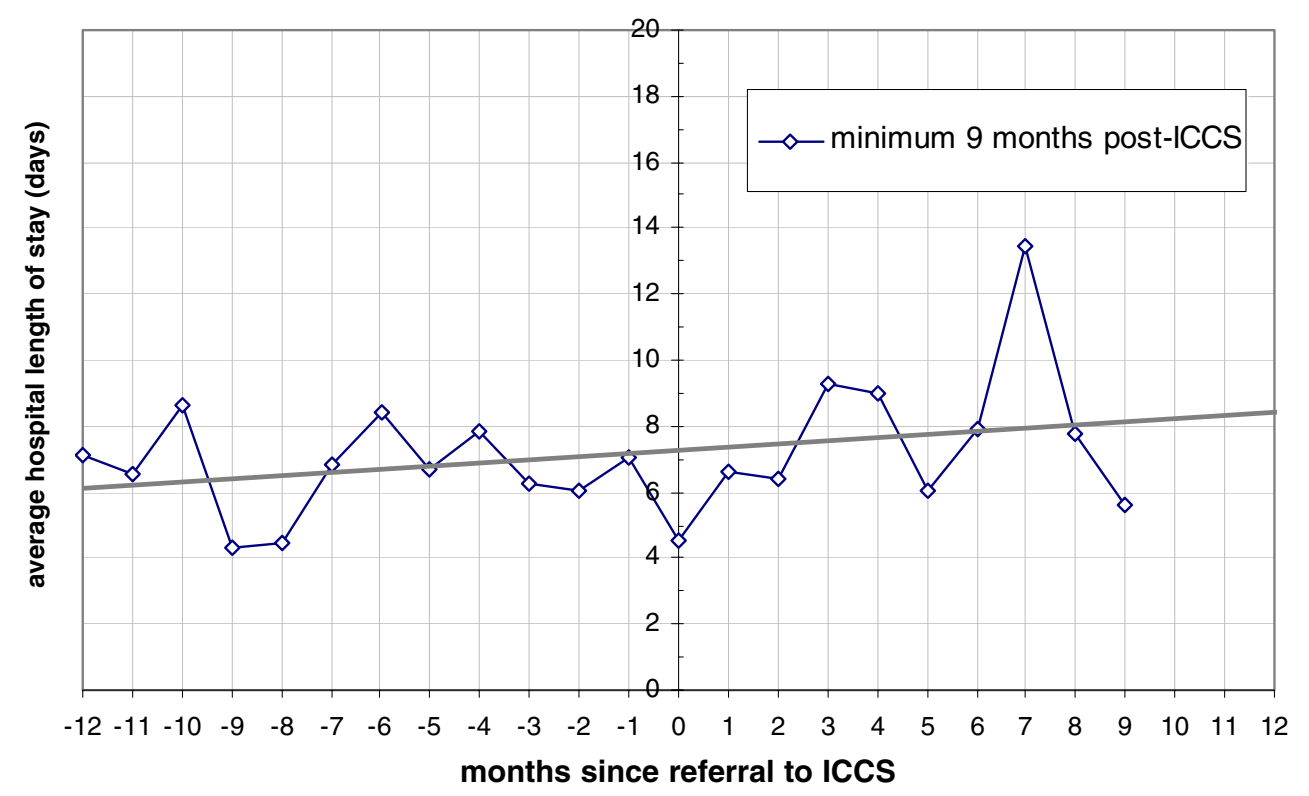

required. On an individual case basis the above calculations show that the average case costs ICCS around $£ 1.5 \mathrm{k}$ in return for health care savings of $£ 10.2 \mathrm{k}$ (upper bound) and $£ 4.8 \mathrm{k}$ (lower bound) in the subsequent 12 months. This does not take account of the cost of services then provided to clients following intervention but as these are of significantly lower cost than a hospital bed, we can be reasonably sure that they are small.

The analysis thus far is based on clients that survive a full 12 months but around $20 \%$ of ICCS clients die in the first year and this needs to be taken into account. In this regard a distinction can be drawn between those that die within weeks or months of referral. We find that these cases experience similar end of life health care costs to the general population with a steep rise in hospital admission, bed-day utilisation and A\&E attendance. Those that die after 6 months may initially show a pattern of reduced admission frequency but then the end-stage pattern takes over. Take for example two typical cases that are referred at the same time with similar history of hospitalisation leading up to referral but one of them dies within 6 months and the other survives. The one that dies consumes bed-days at an accelerated rate using around 30 bed days in the 6 months up to death, whereas the former experiences reduced

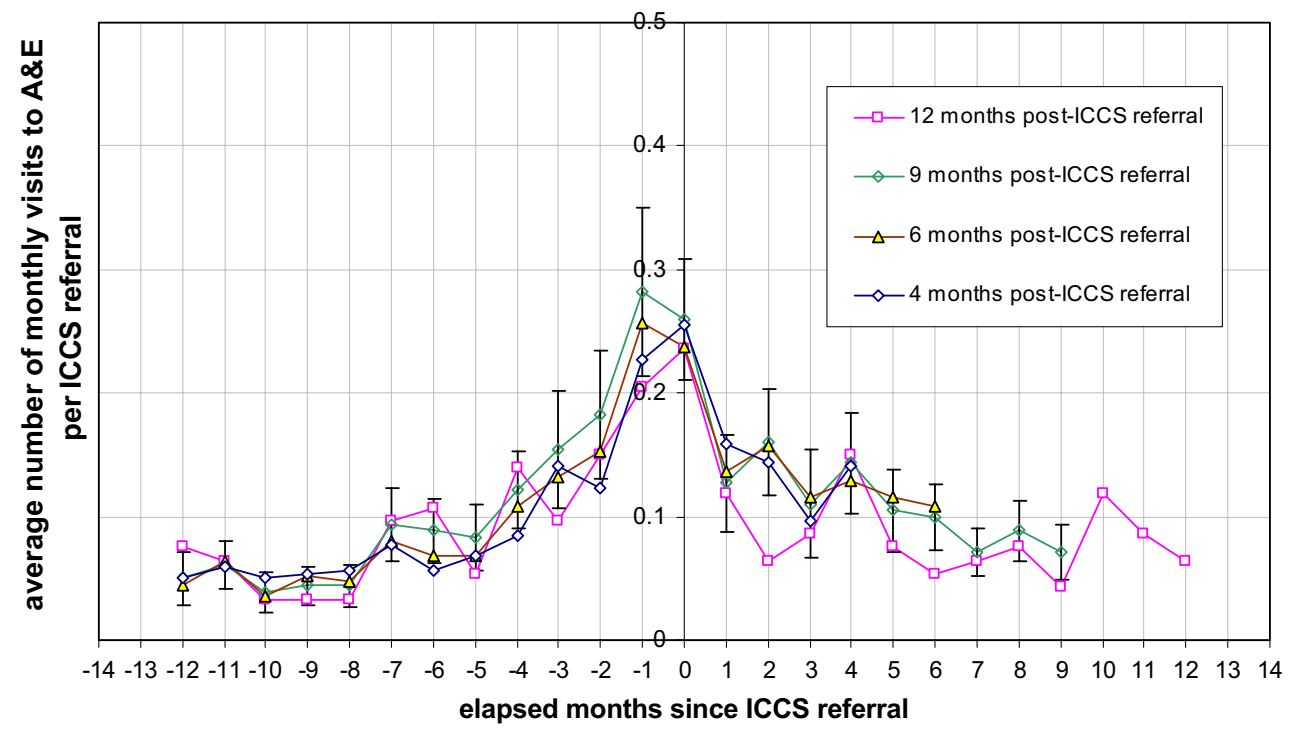

Fig. 8 Pattern of average A\&E visits per client per month based on samples with different start dates and post-referral history 
Table 5 Regression results based on trend lines fitted to A\&E attendance pre- and post-ICCS referral

\begin{tabular}{lcc}
\hline & A\&E analysis & \\
\cline { 2 - 3 } period and statistical model & Constant Log A, A & Slope b \\
\hline Trend line based on actual pre-ICCS A\&E attendance & & \\
-exponential & -1.4035 & 0.1618 \\
S.E & 0.1385 & 0.0196 \\
(t) & $(10.1)$ & $(8.3)$ \\
-linear & 0.2282 & 0.0188 \\
S.E & 0.02 & 0.002833 \\
(t) & $(11.4)$ & $(6.6)$ \\
Trend in actual A\&E attendance 9 months post-ICCS & & -0.1136 \\
-exponential & -1.6528 & 0.0217 \\
S.E & 0.1159 & $(5.2)$ \\
(t) & $(14.3)$ & 0.80 \\
\hline
\end{tabular}

utilisation of around seven bed days compared with 14 bed days in the absence of ICCS. Clearly it would be theoretically possible to devise a correction factor for such cases simply by deducting say $20 \%$ from the savings or even derive a more sophisticated adjustment, but this is arguably unnecessary because of the built-in use of an upper and lower bound trajectory.

\section{Wider impacts of ICCS}

If this analysis is accepted, ICCS shows a good rate of return on the measures described, but this is not acceptable in itself if there are adverse effects on the ability of ICCS clients to remain independently at home and/or on their quality of life. We have already noted that ICCS clients are generally frail with $70 \%$ aged $75+$ and $50 \% 85+$. Initial clinical assessments showed a range of chronic clinical conditions including heart and circulatory disease $(25 \%$ of cases), mobility problems including oedema (17.5\%), arthritis (14.5\%), mental illness (12.7\%), sensory disability (9.7\%), respiratory disease $(9 \%)$, and other $(11.5 \%)$, with $52.8 \%$ having been diagnosed with $2+$ of these conditions. In addition mental depression was found to be more common in younger clients rising to a peak of around $38 \%$ in age band 70-74 (all age average 21.7\%); however, the percentage of clients with cognitive problems rose with age to over $30 \%$ of all clients. As all of the above diagnoses could be labelled long term chronic conditions we did not expect, nor did we find any improvements pre- and post-intervention.

In terms of functional abilities, we found that the most commonly 'failed' ADLs were being able to climb the stairs $(56.3 \%)$, wash alone ( $43 \%$ of cases), and dress alone $(30 \%)$. The ADLs least likely to fail were feeding alone
Fig. 9 Average A\&E attendances per client per month preand post-ICCS referral including prevention effects (one attendance $=£ 200$ )

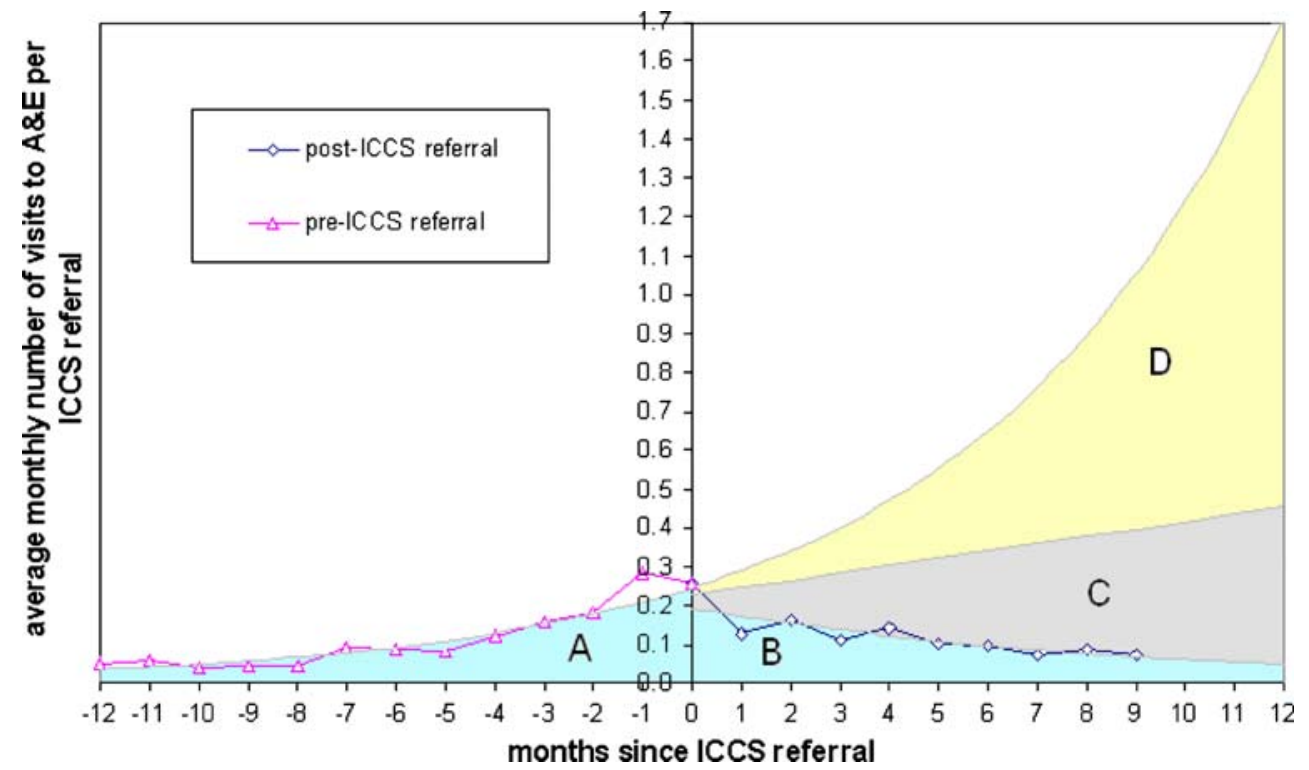


Table 6 Pattern of A\&E attendance before and after intervention (based on throughput of 500 cases per annum; estimated cost per attendance = $£ 200)$

\begin{tabular}{|c|c|c|c|c|}
\hline & A\&E attendance with ICCS service & A\&E attendance per client & total ICCS caseload & $\mathrm{A} \& \mathrm{E}$ cost $(£ \mathrm{~s} 000 \mathrm{~s})$ \\
\hline A & in previous 12 months & 1.30 & 650 & 130,067 \\
\hline $\mathrm{B}$ & 12 month post-referral A\&E attendance & 1.25 & 627 & 125,446 \\
\hline $\mathrm{C}$ & prevented A\&E attendance (lower bound) & -2.84 & $-1,419$ & $-283,754$ \\
\hline $\mathrm{C}+\mathrm{D}$ & prevented A\&E attendance (upper bound) & -7.81 & $-3,906$ & $-781,107$ \\
\hline
\end{tabular}

$(6.9 \%)$, and transferring from bed to chair $(8.7 \%)$. The data indicated that on average the typical ICCS client failed on average 1.4 ADLs per person, or about the same number of chronic conditions. Using information provided in monthly check-ups we examined patterns of ADLs among ICCS clientele to see if there were significant changes from when they were referred to the service until they were discharged with fully complete data available for 277 cases. In the follow-up period we found that slightly more people deteriorated than improved in terms of ADLs, although in some cases such as feeding, transferring from bed to chair or using the toilet, changes for the better or worse tended to be smaller and more or less balance out.

The largest changes for the worse occurred in terms of dressing and washing and climbing stairs, but these were also the three ADLs that had the highest failure rate from the outset suggesting an already advanced stage of decline. However, the direction of change can be for the better and it is noticeable that improvements are possible and do occur in each area of activity. The net change in the percentage failure rate at the outset and at final review is shown in Table 7 and shows the net failure rate is up slightly from $26.2 \%$ to $28.3 \%$, a change of $2.1 \%$ over an average 14 week period. The data do not tell us whether this is a faster or slower rate of change than would have occurred without ICCS, although clearly in this case there would have been no assessment and therefore no support in place. At best therefore we can say that ICCS is broadly neutral with regard to changes in ADLs, that is ADLs are basically unchanged overall but as help is provided through ICCS in the form of services, clients can manage better than they could before (Table 7).

Table 7 ADL failure rate at outset and at last review

\begin{tabular}{lcc}
\hline ADL & $\begin{array}{c}\text { After 1 month } \\
\text { Failure rate \% }\end{array}$ & $\begin{array}{c}\text { At last review } \\
\text { Failure rate \% }\end{array}$ \\
\hline can feed alone & 6.9 & 6.5 \\
can dress alone & 30.0 & 33.9 \\
can wash alone & 43.0 & 46.6 \\
can use the toilet & 12.3 & 12.6 \\
can transfer from bed to chair & 8.7 & 8.7 \\
can climb stairs & 56.3 & 61.4 \\
Overall & $26.2 \%$ & $28.3 \%$ \\
\hline
\end{tabular}

Information obtained on the incidence of falls showed a more encouraging trend than for ADLs. In the first month of service $21 \%$ of cases experienced a 'fall' but this reduced to $14 \%$ of the remaining caseload in the second month, $11 \%$ in the third month, $10 \%$ in the fourth month and $4 \%$ in the fifth month. So the risk of a fall appeared to halve after 2 months, but whether this would have occurred anyway is not completely confirmed since having a fall will tend to make a person more risk averse. In any event any falls reduction is likely to have had an effect on $A \& E$ attendance and also hospital admissions. However, changes in the incidence of falls and ADLs tell us nothing about quality of life changes pre-and post-referral. Data on whether there was an effect was obtained from a separate survey conducted by the POPP national evaluation team at two points in time before and after referral. The results showed that $50 \%$ reported no change in quality of life pre- and postreferral, $30 \%$ an improvement and in $20 \%$ of cases a change for the worse. In summary, therefore, whilst clients with long term conditions do not recover their health or their functional abilities once assigned to ICCS, more people are assisted in living at home, the incidence of falls is reduced and changes in quality of life are broadly neutral to favourable.

\section{Conclusions}

This paper has reported results based on a methodology for evaluating a service, the Integrated Care Co-ordination Service or ICCS, whose aims include keeping older people out of hospital by enabling them to live independently in their own homes by referring them to a range of services. Overall it finds that based on admission avoidance and prevented A\&E attendance the service is highly cost effective. To put this into wider perspective, an ICCS, assuming no other sources of savings, would break even (i.e. savings minus costs), if it prevented five to six beddays per client per year or eight visits to A\&E. In fact it saves between 14 and 29 bed-days a year, in addition to which it makes further significant savings from reduced A\&E attendance. The prevented bed-days equate to a reduction of between 19 and 39 hospital beds and 1.4-3k fewer admissions a year in the $65+$ age group for this area 
of northwest London. This may be compared against the overall number of elective annual admissions in this age group for this area of $15 \mathrm{k}$ a year ${ }^{15}$.

From the evidence of this work such services are unlikely to improve health as such but may well impact on well-being and reduce for example the number of falls. It was not possible to say if there are associated changes in life expectancy as a result of the service, but if so this would clearly have further implications in terms of the economic case. Finally the timing of intervention appears to be a crucial element of the success of the service. When the conditions for referral are met cost effectiveness is more likely to be enhanced as compared with a referral which is either too early or too late. In planning such services afresh there is no direct measure of potential caseload but there are a few benchmarks. One is the number of deaths from all causes each year which could provide an upper bound. In Brent's case it would suggest at least a doubling in referrals, although of course not everyone may be suitable for ICCS.

Local health care providers, social services and voluntary groups have welcomed the research and are committed to using the lessons and principles from the project as they undergo a wider transformation of community services. As previously noted, there is intense interest in the UK health service in finding alternatives to hospital admissions for older people. If such a service as ICCS were to be extended across the country into a 'National Care Co-ordination Service' the potential savings would be substantial, but resources would need to be freed up in the hospital sector to gain the full benefits. The Department of Health has also welcomed the report, with ICCS one of a number of projects from the POPP programme being promoted nationally and discussed with local directors of adult social services. Finally, it is of interest that the political rhetoric surrounding the POPP programme reflects the increasingly received wisdom that by providing integrated health, social care and other local services, it is possible to "enable people to live independently for longer and reduce the incidents that can lead to emergency hospital admissions, and in some cases, a loss of independence" ${ }^{\prime 16}$. This study appears to confirm that belief.

\footnotetext{
$\overline{15}$ Note that this figure may not come down, despite ICCS, if the same beds are filled by other non-electives that have not had ICCS intervention although waiting times for elective admissions could fall as a result.

${ }^{16}$ Speech by Rt Hon Alan Johnson MP, Secretary of State for Health, National Children and Adult Services Conference, 24 October 2008
}

Acknowledgements The author would like to acknowledge the support and encouragement of Ros Howard (former Head of Older People Services at Brent Council), Lesley Braithwaite (Brent POPP Project Manager), Serena Cundari (Brent POPP information officer) Gillian Harper (Director of Operations, Mayhew Harper Associates), the ICCS care co-ordinators, the POPP project Board and Brent Primary Care Trust.

Open Access This article is distributed under the terms of the Creative Commons Attribution Noncommercial License which permits any noncommercial use, distribution, and reproduction in any medium, provided the original author(s) and source are credited.

\section{References}

1. Alder (2008) Disease Management programmes for major depression: Making the financial case. Milliman Research Report, Milliman, London

2. Bowen T, Forte P (2000) Intermediate Care Services for Older People: Estimating Future Workforce Requirements, Unpublished report

3. Byles JE (2000) A thorough going over: evidence for health assessments for older persons. Aust N Z J Public Health 24(2): $117-123$

4. Brent Council (2007) Brent partnerships for older people project12 months on. May 2007, Internal report.

5. Campbell DT, Stanley JC (1966) Experimental and quasi-experimental designs for research. Reprinted from Handbook of Research on Teaching, published in 1963 by Houghton Mifflin Company.

6. Cass Business School (2008) The economic, health and social benefits of care co-ordination for older people The integrated care co-ordination service. Faculty of Actuarial Science and insurance, Cass Business School, City University, London, ISBN: 978-1-905 752-17-1

7. Chang JT, Morton SC, Rubenstein LZ, Mojica WA, Maglione M, Suttorp MJ, Roth EA, Shekelle PG (2004) Interventions for the prevention of falls in older adults: systematic review and metaanalysis of randomised clinical trials. BMJ 328:680. doi:10.1136/ bmj.328.7441.680. (20 March)

8. Coast J, Peters TJ, Inglis A (1996) Factors associated with inappropriate emergency hospital admission in the UK. Int J Qual Health Care 8(1):31-39. doi:10.1093/intqhe/8.1.31

9. Department of Health (2000) NHS plan. Department of Health, England

10. Department of Health (2001) National service framework for older people. Department of Health, England.

11. Forte P, Bowen TT (1997) Improving the balance of elderly care services. In: Cropper S, Forte P (eds) Enhancing health services management. Milton Keynes, Open University Press, pp 71-85. ISBN: 0-335-19634-9

12. Glasby J, Littlechild R (2000) Fighting fires?-emergency hospital admission and the concept of prevention. J Manag Med 14(2):109-118. doi:10.1108/02689230010346501

13. Henderson LR, Scott A (2001) The costs of caring for stroke patients in a GP-led community hospital. An application of programme budgeting and marginal analysis. Health Soc Care Community 9:244-254

14. Mayhew L, Lawrence D (2006) The costs and service implications of substituting intermediate care for acute hospital care. Health Serv Manage Res 19:80-93. doi:10.1258/095148406776829077

15. McCallion GM (1993) Planning care for elderly people using the balance of care model. Health Serv Manage Res 6(4):218-228

16. McDonald AG, Cuddeford GC, Beale M (1974) Balance of care: some mathematical models of the National Health Service. $\mathrm{Br}$ Med Bull 30:262-270 
17. Myers S, Grant RW, Lugn NE, Holbert B, Kvedar J (2006) Impact of home-based monitoring on the care of patients with congestive heart failure. Home Health Care Manage Pract 18(6):444-451. doi:10.1177/1084822306289991

18. Rich MW, Beckham V, Wittenberg C, Leven C, Freedland K, Carney R (1995) A multidisciplinary intervention to prevent the readmission of elderly patients with congestive heart failure. $\mathrm{N}$ Engl J Med 333(18):1190-1195

19. Rubenstein LZ, Stuck AEAE (2001) Preventive home visits for older people: defining criteria for success. Age Ageing 30:107109. doi:10.1093/ageing/30.2.107

20. Steiner A (1997) Intermediate care: A conceptual framework and review of the literature. King's Fund, London, 1997
21. Steiner AB, Vaughan B, Hanford LL (1998) Intermediate care: Approaches to evaluation. King's Fund, London, 1998

22. University of Hertfordshire (2007) National evaluation of partnerships for older people projects: interim report of progress. Briefing paper Cost-Effectiveness - Measuring Effects: Emergency Bed-Day Use. http://www.dh.gov.uk/en/Publicationsandstatistics/Publications/ PublicationsPolicyAndGuidance/DH_079423

23. van Haastregt J, Diederiks JP, van Rossum E, de Witte LP, Crebolder H (2000) Effects of preventive home visits to elderly people living in the community: systematic review. BMJ 320:754 758. doi:10.1136/bmj.320.7237.754

24. Wanless D (2006) Securing good care for older people-Taking a long-term view. King's Fund, London 